\title{
Synthesis of novel heteroditopic carbene-pyridine palladium(II) chloro vinyl complexes. Comparative reactivity of different palladium vinyl derivatives toward transmetalation with alkynyl stannane
}

\author{
Luciano Canovese *, Fabiano Visentin, Carlo Levi, Claudio Santo \\ Dept. Molecular Sciences and Nanosystems, University Ca' Foscari, Venice, Italy
}

\section{A R T I C L E I N F O}

\section{Article history:}

Received 8 February 2013

Accepted 24 March 2013

Available online 29 March 2013

\section{Keywords:}

Heteroditopic carbene-pyridine ligands

Palladium(II) vinyl complexes

Alkyne insertion reactions

Transmetalation reactions

\begin{abstract}
A B S T R A C T
DeC-activated alkynes such as di-t-butyl-ethyne-dicarboxylate (DTA) or the more reactive dimethyl-ethynedicarboxylate (DMA) do not react with palladium(II) chloro methyl complexes bearing heteroditopic carbene-pyridine $(\mathrm{C}-\mathrm{N})$ as spectator ligands to give the corresponding vinyl derivatives. In order to prepare this type of derivatives we resorted to a dedicated synthetic protocol based on the displacement of labile pyridine-thioether ligands of vinyl palladium pyridine-thioeter species by the carbene-pyridine ligand of carbene-pyridine silver chloride complexes. However, the novel carbene-pyridine vinyl complexes obtained by such synthetic protocol, if compared with other palladium vinyl species with similar steric requirements, display a markedly reduced reactivity toward transmetalation with ethynyl-stannane.
\end{abstract}

(c) 2013 Elsevier B.V. All rights reserved.
The steric and electronic characteristics of spectator ligands play an important role in determining the catalytic properties and in general the reactivity of palladium complexes [1]. A catalytic cycle is usually represented as a series of chemical events in which the nature of the spectator ligand might interfere differently at any different step of the overall process and in the catalyst decay [2]. Among different types of spectator ligands used in catalysis, nitrogen heterocyclic carbenes (NHCs) have acquired an increasing importance thanks to the stability to air and moisture that these ligands impart to their derivatives. Consequently the complexes with $\mathrm{NHC}$ as ancillary ligands are often preferred to those bearing phosphine [3].

The insertion of unsaturated molecules through the $\mathrm{Pd}-\mathrm{C}$ bond represents an important step in cross-coupling [4] and co-polymerization reactions [5]. In the past we have been involved in the study of insertion of alkynes in methyl complexes of $\mathrm{Pd}$ (II) bearing pyridylthioether as ancillary ligands giving vinyl derivatives [6]. We therefore decided to investigate the possibility of obtaining new palladium vinyl species with $\mathrm{NHC}$ as spectator ligands. A potential problem affecting such a synthesis might however emerge because of the mutual cis position of the NHC ligands and the vinyl groups which might undergo reductive elimination with consequent decomposition of the complexes $[7,8]$. The use of chelating NHC ligands reduces such a risk since the strain imposed by chelation should contrast the overlapping of orbitals and consequently the decay of the compounds [9].
Thus, we have first synthesized the imidazolium salts $\mathbf{A}, \mathbf{B}$, and $\mathbf{C}$ which were obtained according to published methods as bromide derivatives [10] whereas $\mathbf{D}$, was synthesized by means of a two step procedure consisting in the methylation of 2-hydroxy-6-methyl pyridine by methanesulphonyl chloride followed by nucleophilic attack of the specific imidazole on 2-chloro-6-methyl pyridine in the presence of $\mathrm{KBr}$ in $\mathrm{MeCN}$. Since the palladium precursors used in this study were chloride derivatives, in order to avoid possible transhalogenation products we have converted the bromide into the corresponding chloride salts by means of an ionic exchange resin DOVEX $21 \mathrm{KCL}$ [11]. The chloride silver complexes 1 were obtained by reacting $\mathrm{Ag}_{2} \mathrm{O}$ with the appropriate imidazolium chloride according to the method of Elsevier et al. [12] (see Scheme 1).

The imidazolium salt $\mathbf{D}$ and the silver derivatives $\mathbf{1}$ were characterized by, IR, ${ }^{1} \mathrm{H}$ and ${ }^{13} \mathrm{C}$ NMR spectroscopy (see Supplementary material). In particular the formation of the silver compounds was apparent since the broad signal due the acidic $\mathrm{C} 2 \mathrm{H}$ proton of imidazolium salt at $\mathrm{ca}$. $10 \mathrm{ppm}$ in the ${ }^{1} \mathrm{H}$ NMR spectra disappears whereas ${ }^{13} \mathrm{C}$ NMR experiments display the signals due to the carbene carbon coordinated to the metal at ca. $180 \mathrm{ppm}$.

Furthermore, we have synthesized the complex 2D by reacting the silver carbene derivative 1D with the complex $[\mathrm{Pd}(\mathrm{COD})(\mathrm{Me}) \mathrm{Cl}][13]$ in order to exploit its supposed high reactivity in promoting the alkyne insertion and consequently the direct synthesis of the vinyl species, thanks to the activating presence of a methyl substituent in position 6 of the pyridine ring [6]. Formation of complex 2D is clearly detected from precipitation of $\mathrm{AgCl}$ and its NMR spectrum displaying all the signals attributable to the carbene ligand together with those related to the protons of the methyl group coordinated to palladium at ca. $0.8 \mathrm{ppm}$.

\footnotetext{
* Corresponding author. Tel.: + 39041 2348571; fax: + 390412348517.

E-mail address: cano@unive.it (L. Canovese).
} 


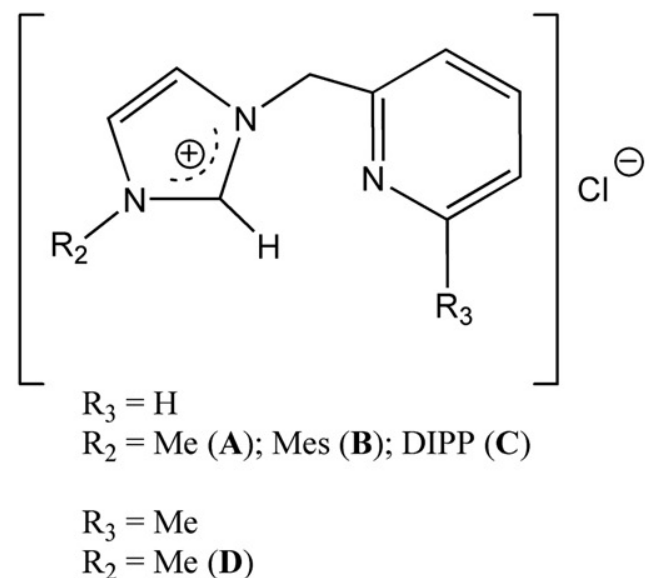<smiles></smiles>

2D

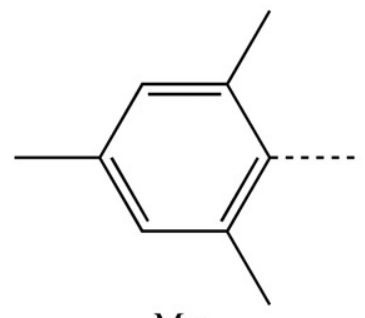

Mes

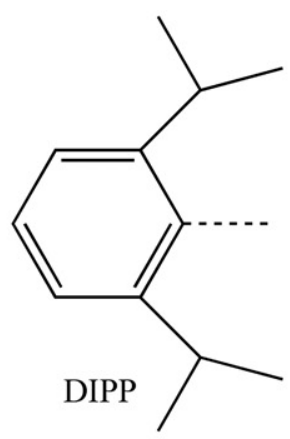<smiles></smiles>

$\mathrm{X}=\mathrm{Cl}$

$\mathrm{R}_{3}=\mathrm{H}$

$\mathrm{R}_{2}=\operatorname{Me~(1A);~Mes~(1B);~DIPP~(1C)~}$

$\mathrm{R}_{3}=\mathrm{Me}$

$\mathrm{R}_{2}=\mathrm{Me}(1 \mathrm{D})$

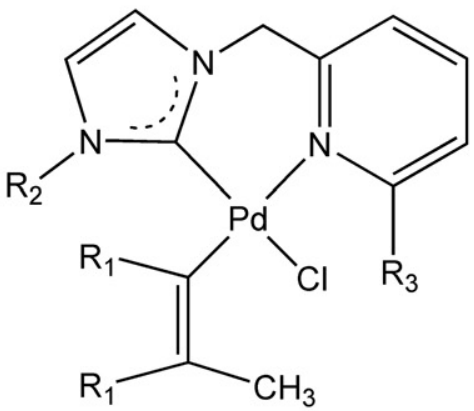

$\mathrm{R}_{1}=\mathrm{COOMe}$

$\mathrm{R}_{3}=\mathrm{H}$

$\mathrm{R}_{2}=\mathrm{Me}(\mathbf{3 A})$; Mes (3B); DIPP (3C)

$\mathrm{R}_{1}=\mathrm{COOMe}$

$\mathrm{R}_{3}=\mathrm{Me}$

$\mathrm{R}_{2}=\mathrm{Me}($ 3D)

$\mathrm{R}_{1}=\mathrm{COO} t \mathrm{Bu}$

$\mathrm{R}_{3}=\mathrm{H}$

$\mathrm{R}_{2}=\mathrm{Me} \mathrm{(4A);} \mathrm{Mes} \mathrm{(4B);} \mathrm{DIPP} \mathrm{(4C)}$

$\mathrm{R}_{1}=\mathrm{COO} t \mathrm{Bu}$

$\mathrm{R}_{3}=\mathrm{Me}$

$\mathrm{R}_{2}=\mathrm{Me}(4 \mathrm{D})$

Scheme 1. Ligands and complexes synthesized and studied.

However, at variance with what we expected complex 2D does not react either with the alkyne di-t-butyl-ethyne-dicarboxylate (DTA) or with the more reactive dimethyl-ethyne-dicarboxylate (DMA) so that the vinyl complexes $\mathbf{3}$ and $\mathbf{4}$ could not be obtained directly. On the basis of our previous experience in the synthesis of $\mathrm{Pd}(0)$ carbene complexes [13b], we took an alternative approach to complexes $\mathbf{3}$ and $\mathbf{4}$ based on the transmetalation between palladium vinyl complexes bearing a labile ancillary ligand and the silver carbene derivatives. Thus, we resorted to our long-standing protocol exploiting the peculiar reactivity of palladium complexes bearing substituted pyridyl-thioethers as spectator ligands. In particular, the complex $[\mathrm{Pd}(\mathrm{MeN}-\mathrm{SPh})(\mathrm{Me}) \mathrm{Cl}]$ (MeN-SPh $=2$-methyl-6-phenylsulfanylmethyl-pyridine) displays a remarkable reactivity toward $\mathrm{Pd}-\mathrm{C}$ bond insertion due to the distortion of the main coordination plane of the complex imposed by the methyl group in position 2 of the pyridine ring [6]. It is noteworthy that complex 2D does not show similar reactivity despite the presence of the 2-methyl substituted pyridine in the ligand scaffold since in this case the increased flexibility of the six-membered ring probably reduces the distortion. Thus, we have reacted the silver carbene complexes 1 and the vinyl palladium derivatives of MeN-SPh synthesized according to the literature [6] in anhydrous $\mathrm{CH}_{2} \mathrm{Cl}_{2}$ under strictly $1: 1$ stoichiometric conditions (Scheme 2).

In any case, the process went smoothly to completion with a reaction time slightly dependent on the steric requirements of the ligands. Thus, methyl derivatives $\mathbf{1 A}$ and $\mathbf{1 D}$ react in a few minutes whereas the reaction time involved in the case of mesityl and di-isopropylphenyl complexes is about $1 \mathrm{~h}$.

The ${ }^{1} \mathrm{H}$ NMR spectra of complexes $\mathbf{3}$ and $\mathbf{4}$ are characterized by the presence of two distinct signals ( $\alpha$ and $\beta$ ) related to the protons of the steric group $-\mathrm{OCH}_{3}$ within 3-4 ppm (complexes 3) and of $-\mathrm{OC}\left(\mathrm{CH}_{3}\right)_{3}$ 
<smiles>[R]C(C)=C([R])[Pb]1(Cl)SCc2cccc(C)[n+]21</smiles><smiles>[R]c1cccc(CC2C=CC([R])C2[Ge]Cl)n1</smiles>

Anhydrous

$\mathrm{CH}_{2} \mathrm{Cl}_{2}$<smiles>[R]C(C)=C([R7])[R]1([X])C([R])=C2C([R2])C=CC2C[n+]2c([R3])cccc21</smiles><smiles>Cc1cccc(CSc2ccccc2)n1</smiles>

Scheme 2. Synthetic protocol for the synthesis of type $\mathbf{3}$ complexes.

within 1- 2 ppm (complexes 4) and by the singlet ascribable to the methyl substituent of the vinyl group in all the complexes at ca. $2.5 \mathrm{ppm}$. Notably, the diastereotopicity of the $\mathrm{CH}_{2}$-Py protons (two doublets centered at ca. $5.5 \mathrm{ppm}, \mathrm{J}=14-15 \mathrm{~Hz}$ ) bears witness to the ligand chelation. In the ${ }^{13} \mathrm{C}$ NMR spectra of complexes 3 the two signals due to the $-\mathrm{OCH}_{3}$ carbons resonate at ca. $50 \mathrm{ppm}$, whereas in the case of complexes 4 the signals of the primary carbons $-\mathrm{OC}\left(\mathrm{CH}_{3}\right)_{3}$ are at ca. $30 \mathrm{ppm}$ and those of the tertiary ones $-\mathrm{OC}\left(\mathrm{CH}_{3}\right)_{3}$ at ca. $80 \mathrm{ppm}$. In all the complexes studied the carbonyl carbons resonate as distinct signals within 165-175 ppm whereas the methyl substituent of vinyl fragment at ca. $20 \mathrm{ppm}$ and the carbene carbon within 170-180 ppm. Quite interestingly, the low temperature ${ }^{1} \mathrm{H}$ NMR spectra of the vinyl derivatives without the methyl substituent in the pyridine ring $(\mathbf{3 A}-\mathbf{C} ; \mathbf{4 A}-\mathbf{C})$ in $\mathrm{CDCl}_{3}$ and $\mathrm{CD}_{2} \mathrm{Cl}_{2}$ are characterized by the splitting of some signals, indicating the presence of two isomers in solution. Since the concentration of the isomers is always comparable and slightly dependent on the ligand and solvent nature (see Table 1 in Supplementary), we suggest that the small difference in energy between the species is due to the presence in solution of two conformers rather than of a couple of $\mathrm{N}-\mathrm{Cl}$ cis and $\mathrm{N}-\mathrm{Cl}$ trans geometric isomers (Scheme 3). As a matter of fact a
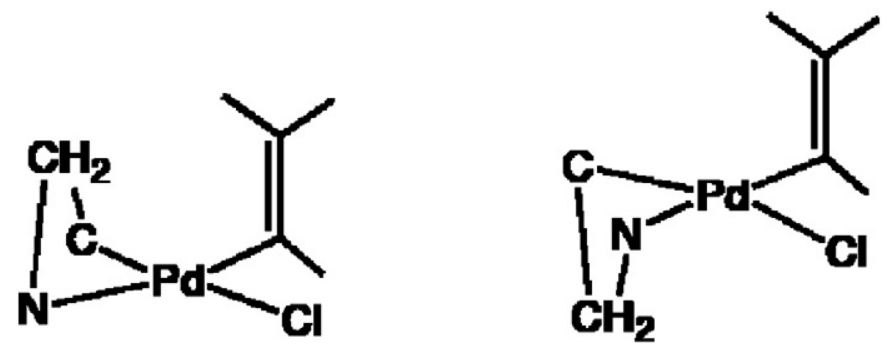

Scheme 3. Schematic representation of the conformation isomers, computational approach based on the DFT calculation indicates that the difference of energy in the case of the conformers of complex $\mathbf{3 A}$ is $\Delta \mathrm{E}=0.07 \mathrm{kcal} \mathrm{mol}^{-1}$ whereas the same difference when the cis and trans isomers are taken into consideration is $\Delta \mathrm{E}=6.8 \mathrm{kcal} \mathrm{mol}^{-1}$. DFT calculations were performed with the $\mathrm{DMol}^{3}[14]$ program, and geometries of the compounds were optimized at DFT PBE [15] level using double numerical polarized basis set (DNP) [16]. Relativistic effects of core electrons were computed using DFT Semi-core Pseudopotentials [17].

The former result fits nicely with the observed isomeric distribution.

In the case of complexes bearing the methyl substituted pyridines as chelating ligands (3D and 4D), owing to the weakening of the $\mathrm{Pd}-\mathrm{N}$ bond due to the distortion imposed by the methyl group from the main plane of the complex [4] the fluxionality of the ring is always operative and therefore no isomers are detected at any accessible temperature.

Furthermore, the ${ }^{1} \mathrm{H}$ NMR spectra of the complexes bearing bulky $\mathrm{R}_{2}$ substituents (3B-C and $\mathbf{4 B}-\mathbf{C}$ ) at $233 \mathrm{~K}$ display the splitting of the signals of the ortho methyl or ortho $i$-propyl groups owing to the hindered rotation of the substituted phenyl fragment around the $\mathrm{N}-\mathrm{C}$ bond.

According to the reaction reported in Scheme 4(A), the Pd(II) vinyl complexes in the presence of ethynyl-stannanes and deactivated olefins yield $\operatorname{Pd}(0)$ olefin derivatives and the extensively conjugated $1-R^{\prime \prime}-1,2-R-2$-arylethynyl ethenes. In this respect the described crosscoupling process can be identified with the final part of a Stille reaction and reasonably proceeds through the formation of type I intermediates which rapidly collapse via reductive elimination to the final products [18]. We therefore decided to compare the influence of different spectator ligands on the reactivity of palladium vinyl complexes by reacting the compounds reported in Scheme 4B with tributyl-phenylethynylstannane in the presence of fumaronitrile [19] in $\mathrm{CDCl}_{3}$ at $298 \mathrm{~K}$. We have chosen the complexes $\mathbf{1 , 2}$ [6] and 3D since it is possible to distinguish the influence on their reactivity of the fragment of the bidentate 

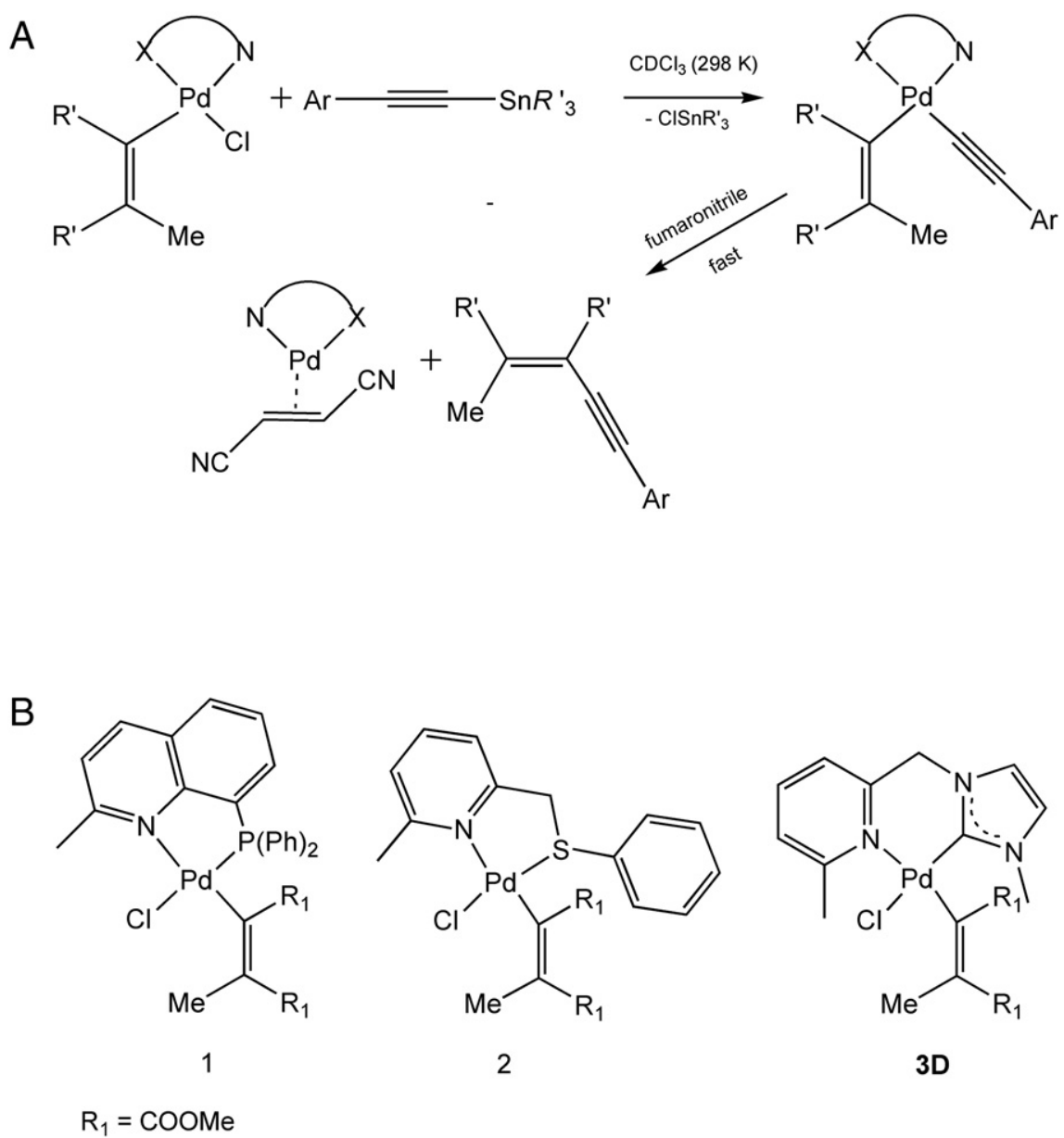

Scheme 4. (A) Transmetalation reaction between palladium vinyl complexes and stannane. (B) Studied Palladium vinyl complexes.

ligand bearing phosphine, thioetheric sulfur or carbene carbon, respectively, all the other substituents to palladium being almost the same.

We have monitored the reaction progress by detecting the intensity of the relevant ${ }^{1} \mathrm{H}$ NMR peaks of the reaction product 2-methyl3-phenylethynyl-but-2-ene dioic acid dimethyl ester and measured the reaction time. The reaction times are:

\section{2(10' )b1(7h ) b 3D (more than 24h).}

The reduced reactivity of complex 3D is clearly due to the comparatively higher $\sigma$-donor capability of the carbene which, while enhancing the charge density on the metal, disfavors the substitution of the chloride with the less electron withdrawing alkenyl group. It is also possible to state that steric hindrance plays a minor role since the less crowed derivative 3D displays the lowest reactivity.

\section{Appendix A. Supplementary material}

Supplementary data to this article can be found online at http:// dx.doi.org/10.1016/j.inoche.2013.03.026.

\section{References}

[1] (a) B.P. Fors, D.A. Watson, M.R. Biscoe, S.L. Buchwald, J. Am. Chem. Soc. 130 (2008) 13552-13554;

(b) D.A. Watson, M. Su, G. Teverovskiy, Y. Zang, J. Garcia-Fontanet, T. Kinzel, S.L Buchwald, Science 325 (2009) 1661-1664;

(c) E.J. Cho, T.D. Senecal, T. Kinzel, Y. Zang, D.A. Watson, S.L. Buchwald, Science 328 (2009) 1679-1681.

[2] J. Tsuji, Palladium Reagents and Catalysis, J. Wiley \& Son, Chichester, 1995.

[3] P. Frémont, N. Marion, S.P. Nolan, Coord. Chem. Rev. 253 (2009) 862-892.
[4] (a) I. Shimuzu, J. Tsuji, J. Chem. Lett. (1984) 203;

(b) M. Ahmar, B. Cazes, J. Gore, Tetrahedron Lett, 25 (1984) 4505-4508;

(c) M. Ahmar, B. Cazes, J.J. Barieux, J. Gore, Tetrahedron 43 (1987) 513-526;

(d) B. Cazes, Pure Appl. Chem. 62 (1990) 1867-1878;

(e) P.W.N.M. van Leeuwen, G. van Koten, Catalysis: an integrated approach to homogeneous, heterogeneous and industrial catalysis, Elsevier, 1993.

[5] J.H. Groen, C.J. Elsevier, K. Vrieze, W.J.J. Smeets, A.L. Spek, Organometallics 15 (1996) 3445-3455, (and refs. therein).

[6] L. Canovese, F. Visentin, G. Chessa, P. Uguagliati, C. Santo, A. Dolmella, Organometallics 24 (2005) 3297-3308.

[7] K.J. Cavell, D.S. McGuinness, Coord. Chem. Rev. 248 (2004) 671-681.

[8] D.S. McGuinness, N. Saedig, B.F. Yates, K.J. Cavell, J. Organomet. Chem. 123 (2001) 4029-4040.

[9] R.E. Douthwaite, M.L. Green, P.J. Silcock, P.T. Gomes, J. Chem. Soc. Dalton Trans. (2002) 1386-1390.

[10] (a) A.A.D. Tulloch, A.A. Danopoulos, S. Winston, s. Kleinhenz, G. Eastham, J. Chem. Soc. Dalton Trans. (2000) 499-4506;

(b) L. Canovese, F. Visentin, C. Levi, C. Santo, V. Bertolasi, Inorg. Chim. Acta 390 (2012) 105-118.

[11] R.H. Crabtree, Organometallics 23 (2004) 2467.

[12] (a) S. Warsink, P. Hauwert, M.A. Siegler, S. Warsink, P. Hauwert, M.A. Siegler, A.L. Spek, C.J. Elsevier, Appl. Organomet. Chem. 23 (2009) 225;

(b) S. Warsink, S.Y.D. Boer, L.M. Jongens, C.-F. Fu, S.-T. Liu, J.-T. Chen, M. Lutz, A.L. Spek, C.J. Elsevier, Dalton Trans. (2009) 7080.

[13] A.A.D. Tulloch, S. Winston, A.A. Danopoulos, G. Eastham, M.B. Hursthouse, Dalton Trans. (2003) 699-708.

[14] (a) B. Delley, J. Chem. Phys. 92 (1990) 508:

(b) B. Delley, J. Chem. Phys. 113 (2000) 7756-7765.

[15] J.P. Perdew, K. Burke, M. Ernzerhof, Phys. Rev. Lett. 77 (1996) 3865-3868.

[16] B. Delley, J. Phys. Chem. A 110 (2006) 13632-13639.

[17] B. Delley, Phys. Rev. B 66 (2002) 155125, (pp. 9).

[18] L. Canovese, F. Visentin, C. Levi, C. Santo, J. Organomet. Chem. 693 (2008) 3324-3330.

[19] The nature of the stabilizing olefin can heavily affect the overall reaction rate. We have chosen fumaronitrile since it allows a reasonable discrimination among the reaction rates of the different palladium complexes and does not react with stannane at variance with the other potential candidate, maleic anhydride (see Ref. 18). 